\title{
INFORMASI DATA REKAM MEDIS PASIEN DI RS BEDAH MITRA KABUPATEN LAMONGAN DENGAN METODE NAIVE BAYES DAN CLUSTERING DALAM PENENTUAN PENYAKIT HYPERTENSI
}

\author{
Kemal Farouq Mauladi \\ Dosen Program Studi Teknik Informatika, Fakultas Teknik, Universitas Islam Lamongan \\ Jl. Veteran No. 53 A Lamongan \\ Telp. (0322) 324706 \\ E-mail: Kemalfarouq_mauladi@yahoo.co.id
}

\begin{abstract}
Medical records have a very broad sense, not only as a recording activity, but has a notion as a system of medical record recordings that start recording during the patient get medical service, followed by handling medical records file that includes the storage and the release of files from the storage for Serve requests or loans if from patients or for other purposes.

Documents of patient medical record data from patient card data, especially patients with hypertension who at the time of control to the partner surgery hospital will from the medical record card document will be scanned or scanned into computer data base as data base storage efficiently and regularly, To then be tested with data mining by using clustering and naive baiyes to determine the number of patients based on the place or area of patients who are frequently treated at the partner surgical hospital.
\end{abstract}

Keywords: Patient Medical Documents, Clustering, Naive bayes.

\section{PENDAHULUAN}

Di Rumah Sakit terdapat unit-unit atau instalasi pelayanan kesehatan antara lain: Unit Gawat Darurat, Unit Rawat Inap, unit pelayanan penunjang medis dan unit pelayanan lain termasuk poliklinik. Poliklinik merupakan salah satu instalasi kesehatan langsung kepada pasien, informasi medis hasil dari anamnesa, riwayat penyakit, pemeriksaan fisik, diagnosa, terapi, dan tindakan poliklinik mulai diperoleh. Catatan-catatan tersebut direkam dalam dokumen rekam medis pasien.

Rekam Medis pasien mempunyai 2 bagian yang perlu diperhatikan yaitu bagian pertama adalah tentang Individu : suatu informasi tentang kondisi kesehatan dan penyakit pasien yang bersangkutan dan sering disebut Patient Record, bagian kedua adalah tentang Manajemen: suatu informasi tentang pertanggung jawaban apakah dari segi manajemen maupun keuangan dari kondisi kesehatan dan penyakit pasien yang bersangkutan Rekam medis juga merupakan kompilasi fakta tentang kondisi kesehatan dan penyakit seorang pasien yang meliputi:

1. Data terdokumentasi tentang keadaan sakit sekarang dan waktu lampau.

2. Pengobatan yang telah dan akan dilakukan oleh tenaga kesehatan profesional secara tertulis.
Metode Naive Bayes adalah klasifikasi statistik yang dapat memprediksi kelas suatu anggota probabilitas untuk klasifikasi bayes sederhana yang lebih dikenal sebagai naïve bayesian Classifier dapat diasumsikan bahwa efek dari suatu nilai atribut sebuah kelas yang diberikan adalah bebas dari atribut-atribut lain. Asumsi ini disebut class conditional independence yang dibuat untuk memudahkan perhitungan-perhitungan pengertian ini dianggap "naive".

Clustering teks berhubungan dengan menemukan sebuah struktur kelompok yang belum kelihatan (tak terpandu atau unsupervised) dari sekumpulan dokumen. Sedangkan pengklasifikasian teks dapat dianggap sebagai proses untuk membentuk golongan-golongan (kelas-kelas) dari dokumen berdasarkan pada kelas kelompok yang sudah diketahui sebelumnya (terpandu atau supervised).

Belum adanya sistem yang digunakan pada informasi data rekam medis pasien di rumah bedah mitra sehat Kabupaten Lamongan dalam mendiagnosis penyakit Hypertensi. membantu dalam pengambilan keputusan perawat atau dokter jaga dalam melihat riwayat penyakit pasien yang sudah diderita sebelumnya, dengan menggunakan suatu metode naive bayes dan clustering yang mampu mendukung dalam pengambilan keputusan dengan cara mengambil 
variable-variable yang dijadikan parameter dalam data rekam medis pasien. sehingga dapat menghasilkan suatu output nilai yang dapat membantu dalam menentukan jumlah penderita penyakit hipertensi di rumah sakit bedah mitra

\section{METODE PENELITIAN}

Pada proses alur sistem flowchart yaitu tentang proses aliran data yang berasal dari petugas rekam medis pasien kemudian data tersebut diolah kedalam sistem di mana data sehat. Dengan sistem baru ini dapat membantu perawat dan dokter mengatasi masalah dalam penanganan penyakit hypertensi dan anjuran obat yang dikosumsi bagi penderita penyakit hypertensi.

yang berhubungan dengan penyakit hypertensi akan dioalah kembali dan kakan dijadikan variabel data nantinya berikut alur flowchart .

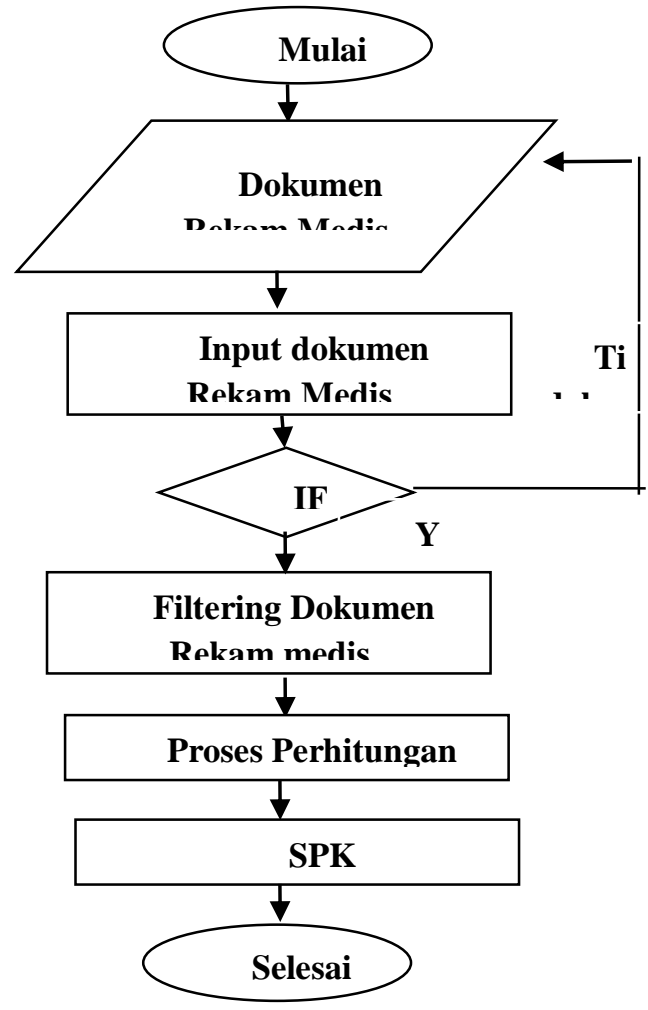

Gambar 1. Alur Flowchart Sistem

Proses data flow diagram pada dokumen rekam medis pasien hypertensi di rumah sakit bedah mitra sehat terdapat beberapa bagian diantaranya yaitu:

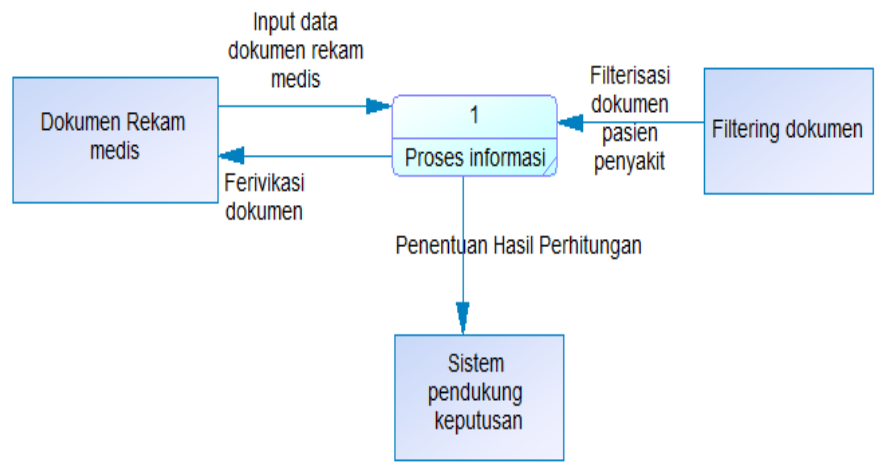

Gambar 2. Kontek Diagram Sistem

Proses data flow diagram level 1 sistem menentukan perhitungan dengan metode naive bayes serta hasil dari perhitungan tersebut akan dijadikan pendukung keputusan pasien tersebut mengenai penyakit hypertensi dengan gejala dan penanganan serta penyembuhan obatnya. 


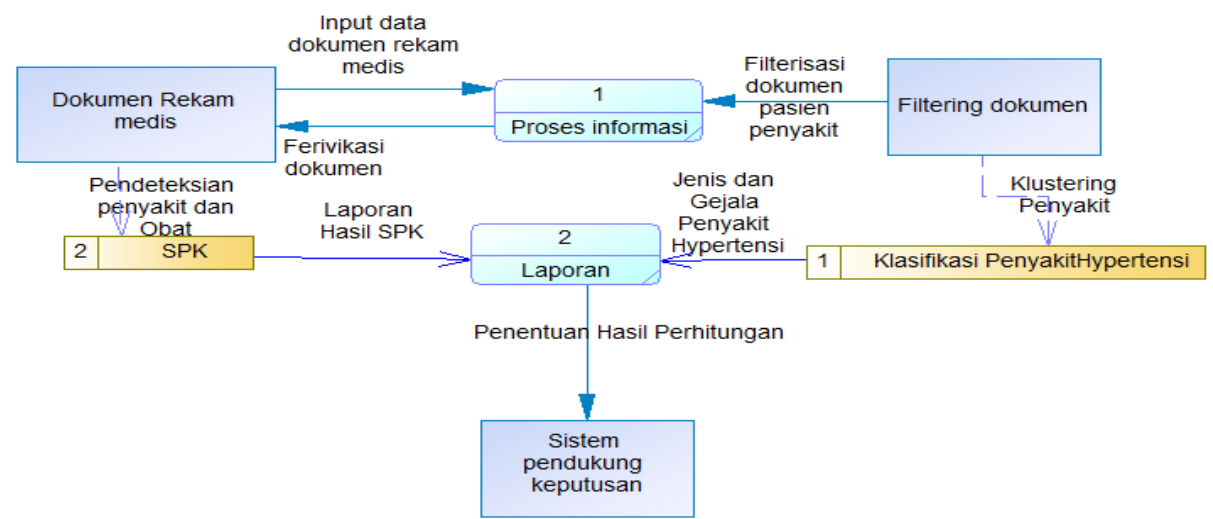

Gambar 3. Data Flow Diagram Level 1



Gambar 4. Desain Modul

Gambar 4 adalah Desain Modul gambaran lsistem yang akan dibangun nanti terdapat beberapa sistem proses.

\section{HASIL DAN PEMBAHASAN}

Data diperoleh rekam medis pada Rs Bedah Mitra Kabupaten Lamongan diaman data diambil dari tahun 2016 sampai dengan januari 2017 data terkumpul sebanyak 500 record data yang terdiri nama pasien, umur pasien, status pasien, gejala pasien.

Sebagai contoh data pasien yang ditampilkan adalah data gejala penyakit hypertensi sebagai berikut:

Tabel 1. Gejala Penyakit Hipertensi

\begin{tabular}{cl}
\hline No & Gejala \\
\hline 1 & Sakit Kepala \\
2 & Leher Cengang \\
3 & Pendarahan dari hidung (mimisan) \\
4 & Rasa berat di tengkuk \\
5 & Susah tidur \\
6 & Mati rasa \\
7 & Punya riwayat diabetes \\
8 & Sesak nafas
\end{tabular}

\begin{tabular}{cll}
\hline No & Gejala \\
\hline 9 & Telinga berdengung & \\
10 & Wajah Kemerahan disertai Kelelahan \\
11 & Gelisah (Vertigo) & \\
12 & Penambahan berat badan berlebih & \\
13 & Sering Buang Air Kecil & \\
14 & Pandangan Kabur atau mata \\
& berkunang-kunang & \\
15 & Pusing \\
16 & Jantung Berdebar \\
17 & Pucat \\
18 & Pingsan \\
19 & Susah Bernafas \\
20 & Punya Riwayat Penyakit Ginjal & \\
\hline
\end{tabular}

Pada Tabel 1 gejala penyakit yang sering terjadi pada pasien di rumah sakit bedah mitra Kabupaten Lamongan berdasarkan dokumen rekam medis pasien.

\begin{tabular}{ccc}
\multicolumn{3}{c}{ Tabel 2. Rentang Usia Pasien } \\
\hline No & Usia & Jumlah Penderita \\
\hline 1 & 30 & 25 \\
2 & 40 & 175 \\
3 & 50 & 230 \\
4 & $>50$ & 70 \\
\hline
\end{tabular}


Pada Tabel 2 Rentang usia yang paling banyak mengidap gejala penyakithypertensi pada kisaran usia 40 sampai 50 Tahun.

\begin{tabular}{lc}
\multicolumn{2}{c}{ Tabel 3. Perolehan (Rule) } \\
\hline \multicolumn{1}{c}{ Varibel } & Nilai \\
& Bobot \\
\hline Definitely not (pasti tidak) & -1.0 \\
Almost Certainly not (hampir pasti & -0.8 \\
tidak) & \\
Probably not (kemungkinan besar & -0.6 \\
tidak) & \\
Maybe not (mungkin tidak) & -0.4 \\
Unknown (tidak tahu) & -0.2 to \\
& 0.2 \\
Maybe (mungkin) & 0.4 \\
Probably (kemungkinan besar) & 0.6 \\
Almost certainly (hampir pasti) & 0.8 \\
Definitely (pasti) & 1.0 \\
\hline
\end{tabular}

Pada Tabel 3 dari hasil perolehan item varibel yang akan dihasilkan rule dengan pembobotan nilai yang sudah dihitung dengan menggunakan metode naive bayes dari perhitungan tersebut maka akan dilanjutkan dengan membuat clustering atau pemetaan item data penyakit hypertensi yang paling sering berobat atau rentang usia yang sering terkena penyakit hypertensi.

\begin{tabular}{cccccccccc}
\hline $\mathrm{X} 1$ & $\mathrm{X} 2$ & $\mathrm{X} 3$ & $\mathrm{X} 4$ & $\mathrm{X} 5$ & $\mathrm{X} 6$ & $\mathrm{X} 7$ & $\mathrm{X} 8$ & $\mathrm{X} 9$ & $\mathrm{X} 10$ \\
\hline $\mathrm{Y}$ & $\mathrm{T}$ & $\mathrm{T}$ & $\mathrm{Y}$ & $\mathrm{T}$ & $\mathrm{Y}$ & $\mathrm{Y}$ & $\mathrm{Y}$ & $\mathrm{T}$ & $\mathrm{T}$ \\
$\mathrm{T}$ & $\mathrm{Y}$ & $\mathrm{Y}$ & $\mathrm{Y}$ & $\mathrm{T}$ & $\mathrm{T}$ & $\mathrm{T}$ & $\mathrm{Y}$ & $\mathrm{T}$ & $\mathrm{T}$ \\
$\mathrm{T}$ & $\mathrm{T}$ & $\mathrm{T}$ & $\mathrm{Y}$ & $\mathrm{Y}$ & $\mathrm{Y}$ & $\mathrm{Y}$ & $\mathrm{T}$ & $\mathrm{T}$ & $\mathrm{Y}$ \\
$\mathrm{Y}$ & $\mathrm{Y}$ & $\mathrm{Y}$ & $\mathrm{Y}$ & $\mathrm{T}$ & $\mathrm{T}$ & $\mathrm{T}$ & $\mathrm{T}$ & $\mathrm{Y}$ & $\mathrm{Y}$ \\
$\mathrm{T}$ & $\mathrm{T}$ & $\mathrm{T}$ & $\mathrm{Y}$ & $\mathrm{Y}$ & $\mathrm{T}$ & $\mathrm{T}$ & $\mathrm{Y}$ & $\mathrm{Y}$ & $\mathrm{Y}$ \\
\hline
\end{tabular}

Keterangan :

$\mathrm{X}_{1}=$ Sakit Kepala

$\mathrm{X}_{2}=$ Leher Cengang

$\mathrm{X}_{3}=$ Rasa berat di tengkuk

$\mathrm{X}_{4}=$ Susah tidur

$\mathrm{X}_{5}=$ Mati rasa

$\mathrm{X}_{6}=$ Punya riwayat diabetes

$\mathrm{X}_{7}=$ Wajah Kemerahan disertai Kelelahan

$\mathrm{X}_{8}=$ Pusing

$\mathrm{X}_{9}=$ Jantung Berdebar

$\mathrm{X}_{10}=$ Susah Bernafas

$\mathrm{Y}=\mathrm{Ya}$

$\mathrm{T}=$ Tidak
Menghitung jumlah data yang terkena penyakit hypertensi

$$
\begin{aligned}
& \mathrm{P}(\mathrm{Y})=250 \\
& \mathrm{P}(\mathrm{Y}=\mathrm{YA})=20 / 250=0,08
\end{aligned}
$$$$
\mathrm{P}(\mathrm{Y}=\mathrm{TIDAK})=75 / 250=0,3
$$

Menghitung probabilitas per variabel $\mathrm{X}$ terhadap variabel $Y$

$$
\begin{gathered}
\mathrm{P}(\mathrm{X} 1=\mathrm{YA} \mid \mathrm{Y}=\mathrm{YA})=25 / 30=0,834 \\
\mathrm{P}(\mathrm{X} 3=\mathrm{SESAK} N \mathrm{NAFAS} \mid \mathrm{Y}=\mathrm{YA})=40 / 175 \\
=0,228 \\
\mathrm{P}(\mathrm{X} 4=\mathrm{TIDAK} \mid \mathrm{Y}=\mathrm{YA})=50 / 230=0,217 \\
\mathrm{P}(\mathrm{X}=\mathrm{TIDAK} \mid \mathrm{Y}=\mathrm{YA})=50 / 70=0, \\
\mathrm{P}(\mathrm{X} 6=\mathrm{YA} \mid \mathrm{Y}=\mathrm{YA})=50 / 175=0,714 \\
\mathrm{P}(\mathrm{X} 7=\mathrm{TIDAK} \mid \mathrm{Y}=\mathrm{YA})=25 / 230=0,108 \\
\mathrm{P}(\mathrm{X} 8=\mathrm{YA} \mid \mathrm{Y}=\mathrm{YA})=175 / 230=0,76 \\
\mathrm{P}(\mathrm{X}=\mathrm{TIDAK} \mid \mathrm{Y}=\mathrm{YA})=70 / 175=0,4
\end{gathered}
$$

Form utama terdiri dari enam (6) form utama aplikasi yaitu: sistem, master, Dokumen Rekam Medis Pasien, Filtering, data mining Clustering, dan admin. Form ini berfungsi untuk menghubungkan semua fasilitas dari sistem.



Gambar 5. Form Menu Utama

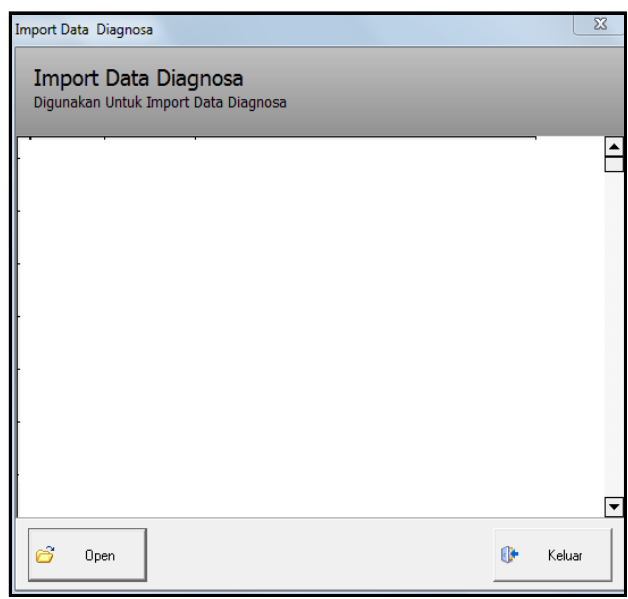

Gambar 6. Dokumen Rekam Medis 
Gambar 6 berfungsi untuk melakukan import data rekam medik pasien dari tabel utama dokumen rekam medik pasien ke tabel aplikasi ini.

Gambar 7 digunakan untuk menampilkan proses perhitungan dalam naive bayes pada proses ini dokumen yang berasal dari data rekam medis pasien yang di inputkan oleh pegawai rekam medis nantinya akan dihitung jumlah jenis penyakit hypertensi pasien.

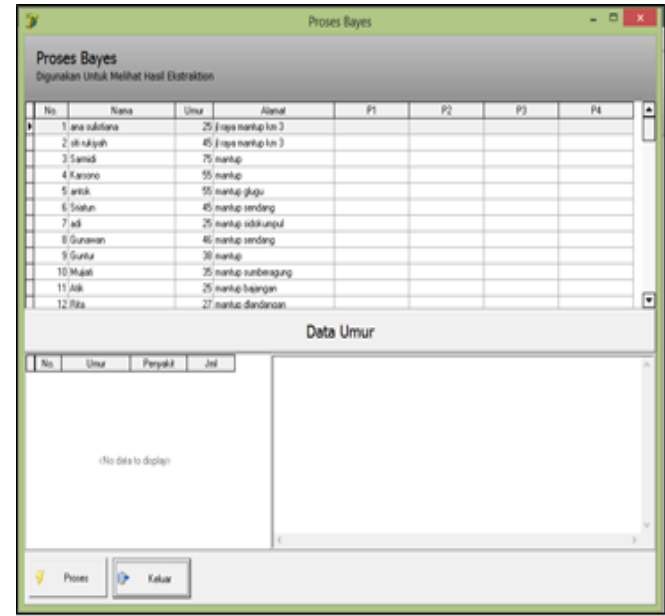

Gambar 7. Proses Naive Bayes

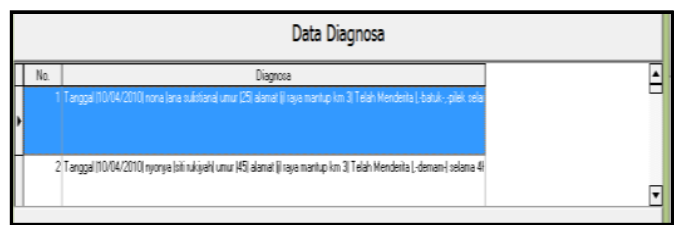

Gambar 8. Proses Clustering

Form Clustering ini digunakan untuk mencari dokumen pasien dengan gejala-gejala hypertensi pasien mulai dari usia pasien pola makanan pasien dan dari proses ini nantinya akan diketahui penanganan dan obat untuk pasien.

\section{KESIMPULAN}

Pada penelitian data rekam medis pasien di rs bedah mitra sehat dengan metode naive bayes dan clustering didapat bebrapa gejala jenis penyakit tersebut dengan beberapa foktor yaitu usia dan pola makan dari pasien pada proses metode clustiring sebagai penentuan pendukung keputusan usia pasien yang sering terkena penyakit hypertensi adalah di usia 45 sampai dengan 50 tahun ke atas.

\section{REFERENSI}

[1] Abidi. 2001. Manajemen Pengetahuan dalam Perawatan Kesehatan. Bandung.
[2] Destuardi. Klasifikasi Emosi Untuk teks Bahasa Indonesia Menggunakan Metode Naive Bayes. Surabaya 13/Agustus/2009.

[3] Irwan Budiman, Toni Prahasto, dan Yuli Christyono. Data Clustering Menggunakan Metodologi Crisp-Dm untuk Pengenalan Pola Proporsi Pelaksanaan Tridharma. Seminar Nasional Aplikasi Teknologi Informasi 2012 (SNATI 2012). Yogyakarta.

[4] Prasetyo, Eko. 2012. Data Mining Konsep dan Aplikasi menggunakan MATLAB. Andi. Yogyakarta.

[5] Nugroho, Bunafit. 2014. Aplikasi Sistem Pakar Dengan PHP Dan Editor Dreamweaver. Gava Media. Yogyakarta.

[6] Sharon Gondo Diputro. 2007. Rekam Medis dan Sistem Informasi Kesehatan di Pelayanan Kesehatan Primer. Bandung. 
Halaman ini sengaja dikosongkan 